\title{
Changes in the Presentation of Incident Gout and the Risk of Subsequent Flares: A Population-based Study over 20 Years
}

\author{
Mohanad M. Elfishawi, Nour Zleik, Zoran Kvrgic, Clement J. Michet Jr., Cynthia S. Crowson (D, \\ Eric L. Matteson, and Tim Bongartz
}

\begin{abstract}
Objective. To examine whether a change in the presentation of incident gout happened over the last 20 years and to determine the risk of subsequent gout flares after an initial gout attack.

Methods. All incident cases of gout were identified among residents of Olmsted County, Minnesota, diagnosed in 1989-1992 and 2009-2010 according to the earliest date fulfilling the 1977 American Rheumatism Association preliminary criteria, or the New York or Rome criteria for gout. Patients in both cohorts were then followed for up to 5 years. Cumulative incidence and person-year methods were used to compare flare rates, and conditional frailty models were used to examine predictors.

Results. A total of 429 patients with incident gout (158 patients in 1989-1992 and 271 patients in 2009-2010) were identified and followed for a mean of 4.2 years. The majority of patients were male $(73 \%)$ and the mean age (SD) at gout onset was 59.7 (17.3) years. Classic podagra decreased significantly from $74 \%$ to $59 \%$ (p < 0.001). Cumulative incidence of first flare was similar in both cohorts (62\% vs $60 \%$ by 5 yrs in 1989-1992 and 2009-2010, respectively; $p=0.70$ ), but overall flare rate was marginally higher in 2009-2010 compared to 1989-1992 (rate ratio: 1.24). Hyperuricemia (HR 1.59) and kidney disease (HR 1.34) were significant predictors of future flares.

Conclusion. Gout flares were common in both time periods. Hyperuricemia and kidney disease were predictors of future flares in patients with gout. Podagra as a presentation of gout has become relatively less frequent in recent years. (First Release December 1 2019; J Rheumatol 2020;47:613-18; doi:10.3899/jrheum.190346)
\end{abstract}

Key Indexing Terms:

GOUT

FLARES

EPIDEMIOLOGY

From the Department of Medicine, Icahn School of Medicine at Mount Sinai, New York City Health + Hospitals, Jamaica, New York; Division of Rheumatology, and Division of Biomedical Statistics and Informatics, and Division of Epidemiology, Department of Health Sciences Research, Mayo Clinic College of Medicine, Rochester, Minnesota; Division of

Rheumatology, Augusta University, Atlanta, Georgia; Department of Emergency Medicine, Vanderbilt University, Nashville, Tennessee, USA.

This work was made possible using the resources of the Rochester Epidemiology Project, which is supported by the US National Institute on Aging of the National Institutes of Health $(\mathrm{NIH})$ under Award Number R01AG034676 and Clinical and Translational Science Awards Grant Number UL1 TR000135 from the National Center for Advancing Translational Sciences, a component of the NIH. The content is solely the responsibility of the authors and does not necessarily represent the official views of the NIH.

M.M. Elfishawi, MBBCh, Department of Medicine, Icahn School of Medicine at Mount Sinai, New York City Health + Hospitals/Queens, and Division of Rheumatology, Mayo Clinic College of Medicine; N. Zleik, $M D$, Division of Rheumatology, Augusta University; Z. Kvrgic, CCRP, Department of Medicine, Icahn School of Medicine at Mount Sinai, New York City Health + Hospitals/Queens; C.J. Michet Jr., MD, Division of Rheumatology, Mayo Clinic College of Medicine; C.S. Crowson, PhD, Division of Rheumatology, and Division of Biomedical Statistics and Informatics, Department of Health Sciences Research, Mayo Clinic College of Medicine; E.L. Matteson, MD, MPH, Division of

Rheumatology, and Division of Epidemiology, Department of Health Sciences Research, Mayo Clinic College of Medicine; T. Bongartz, MD, MS, Division of Rheumatology, Mayo Clinic College of Medicine, and Department of Emergency Medicine, Vanderbilt University.

Address correspondence to M.M. Elfishawi, Department of Medicine,
Icahn School of Medicine at Mount Sinai, New York City Health + Hospitals/Queens, 82-68 164th St., Jamaica, New York 11432, USA. E-mail: Mohanad.Elfishawi@mssm.edu Accepted for publication June 26, 2019.

Gout has surpassed rheumatoid arthritis as the most common form of inflammatory arthritis in the United States ${ }^{1}$. The rising incidence and prevalence of gout have been demonstrated in several studies and among different populations ${ }^{2,3,4,5,6,7}$. In addition, we and others have shown that the burden of comorbidities in patients diagnosed with gout has changed $2,3,4,5,6,7$. Over the last 20 years, patients with gout have developed a higher likelihood of also being affected by obesity, hypertension, diabetes, hyperlipidemia, and renal disease $^{2,3,4,5,6,7}$. It is unclear whether these changes in the occurrence of comorbidities at the time of gout diagnosis have been associated with a change in the clinical presentation of gout itself.

With this study, we examined possible changes in the clinical presentation of incident gout attacks over the last 20 years. Further, we determined the likelihood of subsequent flares after a first attack of gout and investigated predictors of subsequent flares.

Personal non-commercial use only. The Journal of Rheumatology Copyright @ 2020 . All rights reserved. 


\section{MATERIALS AND METHODS}

Gout cohort assembly. The Rochester Epidemiology Project (REP) is a medical record linkage system that gathers medical records from all healthcare providers in Olmsted County, Minnesota ${ }^{8}$. The REP provides ready access to medical records from the Mayo Clinic, the Olmsted Medical Center and its affiliated hospitals, local nursing homes, as well as a few private practitioners. Inpatient and outpatient records are included in the REP, allowing a nearly complete collection of all the records for the population and making the population of Olmsted County well suited for population-based studies.

Using the resources of the REP, residents of Olmsted County, Minnesota, age $\geq 18$ years, were screened for a potential diagnosis of gout using diagnostic codes (International Classification of Diseases, 9th revision: code 274.x $)^{2}$. Two time intervals were chosen separated by 20 years (January 1 , 1989-December 31, 1992, and January 1, 2009-December 31, 2010). During these periods, cases were included as incident gout cases at the earliest date they fulfilled any of the 3 sets of gout criteria (1977 American Rheumatism Association preliminary criteria for gout ${ }^{9}$, Rome criteria ${ }^{10}$, or the New York criteria $^{11}$ ). The medical records for each potential patient (outpatient and inpatient) were reviewed for ascertainment of gout diagnosis. Demographic, laboratory, and clinical data were abstracted by medical record review as previously described ${ }^{2}$. The study was approved by the institutional review board at both the Mayo Clinic (ID: 12-007239) and the Olmsted Medical Center (ID: 018-OMC-15). Informed consent was waived for minimal risk features of the study.

Flare definition. Identified patients with an incident diagnosis of gout were followed up for 5 years, death, or migration out of Olmsted County, whichever came first. Medical records were reviewed for the occurrence of subsequent flares, which were defined as follows: any provider contact (including phone calls mentioning gout flare or asking for prescription medication) for acute musculoskeletal pain AND provider diagnosis of an acute gout attack as the source for the patient's pain. A period of 30 days was required between each gout flare and the next possible flare.

Statistical methods. Descriptive statistics (means, percentages, etc.) were used to summarize data. Patient characteristics were compared between cohorts using chi-square and rank-sum tests. The rate of subsequent gout flares was calculated as the total number of flares divided by the total person-years (PY) of observation in each cohort. Assuming the rates followed a Poisson distribution, 95\% CI for the rates were obtained. Conditional frailty models with random subject effects (accounting for multiple flares per subject) were used to investigate risk factors for subsequent gout flares ${ }^{12}$. Each HR was obtained from a univariable model. Smoothing splines were used to examine the possibility of nonlinear trends in continuous risk factors [e.g., body mass index (BMI) and serum uric acid]. Cumulative incidence methods adjusting for the competing risk of death were used to estimate the time to first subsequent flare after incidence of gout. Analyses were performed using SAS version 9.4 (SAS Institute) and R 3.1.1 (R Foundation for Statistical Computing).

\section{RESULTS}

We identified a total of 429 patients with incident gout, 271 patients in the 2009-2010 time period, and 158 patients in the 1989-1992 time period. The majority of the patients were males and of white ancestry (Table 1). BMI increased significantly in the 2009-2010 cohort compared to the 1989-1992 cohort (mean 32 vs $28.6 \mathrm{~kg} / \mathrm{m}^{2}$, respectively; p < 0.001). Similarly, associated comorbid conditions such as diabetes mellitus, hypertension, hyperlipidemia, and kidney disease were significantly increased in the later cohort. Isolated podagra [first metatarsophalangeal (MTP) arthritis] as the initial presentation of gout has become significantly less common among more recent patients (74\% vs 59\%; $\mathrm{p}=0.001$ ). Similarly, the presence of any podagra (isolated or with other joint involvement) has decreased from $80 \%$ in the 1989-1992 cohort to $67 \%$ in the 2009-2010 cohort $(p=0.004)$. Involvement of small finger and foot joints other than the first MTP during the initial attack has become more common in the more recent cohort.

During followup, 158 patients in the 2009-2010 cohort and 90 patients in the 1989-1992 cohort developed gout flares. The cumulative incidence of the first subsequent gout flare was similar in both cohorts $(\mathrm{p}=0.70$; Figure 1 , upper panel). During the first year after gout incidence, 30\% (95\% CI $22-37 \%$ ) of patients in the 1989-1992 cohort and 37\% (95\% CI 31-43\%) of patients in the 2009-2010 cohort experienced a gout flare. By 5 years after gout incidence, $62 \%$ (95\% CI 54-70\%) of the 1989-1992 cohort and 60\% (95\% CI 54-66\%) of the 2009-2010 cohort had at least 1 subsequent gout flare.

In the 5-year followup, 185 flares occurred in the 1989-1992 cohort, while 397 flares occurred in the 2009-2010 cohort. Despite the similarity between the cohorts in the overall rates of first subsequent flares, the incidence of all subsequent flares increased from 2.8 per $10 \mathrm{PY}$ (95\% CI 2.4-3.3) to 3.5 per $10 \mathrm{PY}$ (95\% CI 3.2-3.9), which corresponds to a $24 \%$ increase in the incidence of subsequent flares (rate ratio $1.24,95 \%$ CI 1.04-1.47) in patients diagnosed with gout. Most of the excess flares in the 2009-2010 time period occurred during the first 2 years after gout incidence (Figure 1, lower panel). However, when adjusted for multiple flares within the same patient, this association was attenuated (HR 1.14, 95\% CI 0.95-1.36; $\mathrm{p}=$ $0.15)$, indicating that a small number of patients with unusually high numbers of flares in the 2009-2010 cohort influenced the unadjusted comparisons between cohorts.

There has been some change in the clinical characteristics of subsequent flares that are similar to the changes observed for the first gout attack. Isolated podagra has decreased from $70 \%$ in the earlier cohort to $45 \%$ in the 2009-2010 cohort $(\mathrm{p}<0.001)$. Monoarticular presentation has significantly lessened over this time period, from 92\% in the 1989-1992 cohort to $75 \%$ in the $2009-2010$ cohort ( $p<0.001$ ), with more patients experiencing oligo/polyarticular presentations in the later time period (Table 2).

Several demographic and clinical variables were evaluated as possible predictors of subsequent flares. Serum uric acid levels $\geq 7 \mathrm{mg} / \mathrm{dl}$ for males and $\geq 6 \mathrm{mg} / \mathrm{dl}$ for females at the time of first flare were found to pose a significant risk for subsequent flares (HR 1.59, 95\% CI 1.16-2.18). For every $1 \mathrm{mg} / \mathrm{dl}$ increase in serum uric acid level, the risk of subsequent flares increased by $13 \%$. Among comorbidities, only the presence of renal insufficiency was significantly associated with subsequent gout attacks (HR 1.34, 95\% CI 1.12-1.61; Table 3). None of the clinical characteristics at the time of incident gout such as specific joint or polyarticular involvement were significantly associated with subsequent flare risk.

Personal non-commercial use only. The Journal of Rheumatology Copyright @ $\odot 2020$. All rights reserved 
Table 1. Characteristics of patients among Olmsted County, Minnesota, residents with incident gout in 1989-1992 compared with 2009-2010 at the time of incident gout attack.

\begin{tabular}{|c|c|c|c|}
\hline Characteristics & $\begin{array}{l}1989-1992 \\
\mathrm{n}=158\end{array}$ & $\begin{array}{l}2009-2010 \\
\mathrm{n}=271\end{array}$ & $\mathrm{p}$ \\
\hline Age at diagnosis, yrs, mean \pm SD & $59.3 \pm 17.9$ & $60.0 \pm 17.0$ & 0.68 \\
\hline Sex, male & $116(73)$ & $196(72)$ & 0.81 \\
\hline Race and ethnicity, white & $149(94)$ & $244(90)$ & 0.17 \\
\hline Length of followup, yrs, mean \pm SD & $4.1 \pm 1.6$ & $4.2 \pm 1.2$ & - \\
\hline \multicolumn{4}{|l|}{ Comorbidities at incidence attack } \\
\hline Body mass index, $\mathrm{kg} / \mathrm{m}^{2}$, mean $\pm \mathrm{SD}$ & $28.6 \pm 5.3$ & $32.0 \pm 6.8$ & $<0.001$ \\
\hline Kidney disease & $18(11)$ & $77(28)$ & $<0.001$ \\
\hline Hypertension & $86(54)$ & $188(69)$ & 0.002 \\
\hline Diabetes mellitus & $9(6)$ & $68(25)$ & $<0.001$ \\
\hline Hyperlipidemia & $33(21)$ & $164(61)$ & $<0.001$ \\
\hline Trauma to the affected joint within preceding 4 weeks & $7(4)$ & $30(11)$ & 0.017 \\
\hline Serum uric acid level prior to incident attack, mean \pm SD & $8.1 \pm 1.6$ & $8.4 \pm 2.7$ & 0.58 \\
\hline$>1$ joint involved at incident attack & $13(8)$ & $28(10)$ & 0.47 \\
\hline Isolated podagra & $117(74)$ & $159(59)$ & 0.001 \\
\hline Podagra (with or without other joint involvement) & $126(80)$ & $181(67)$ & 0.004 \\
\hline Hand, small joints & $6(4)$ & $21(8)$ & 0.10 \\
\hline Wrist & $3(2)$ & $5(2)$ & 0.97 \\
\hline Knee & $7(4)$ & $17(6)$ & 0.42 \\
\hline Foot, small joints (excluding first MTP) & $7(4)$ & $35(13)$ & 0.004 \\
\hline Ankle & $18(11)$ & $33(12)$ & 0.81 \\
\hline Mid-foot & $4(3)$ & $6(2)$ & 0.83 \\
\hline Other (elbow)* & $4(3)$ & $1(0.4)$ & 0.044 \\
\hline \multicolumn{4}{|l|}{ Treatment of incident flare } \\
\hline Intraarticular GC injection & $1(1)$ & $42(15)$ & $<0.001$ \\
\hline Oral GC & $2(1)$ & $59(22)$ & $<0.001$ \\
\hline Colchicine & $18(11)$ & $34(13)$ & 0.72 \\
\hline NSAID & $137(87)$ & $188(69)$ & $<0.001$ \\
\hline $\begin{array}{l}\text { Starting uric acid-lowering therapy in first } 30 \text { days after } \\
\text { incident attack }\end{array}$ & $11(7)$ & $49(18)$ & 0.001 \\
\hline Ever used uric acid-lowering therapy & $55(35)$ & $152(56)$ & $<0.001$ \\
\hline Allopurinol & $54(34)$ & $129(48)$ & 0.007 \\
\hline Losartan & $0(0)$ & $43(16)$ & $<0.001$ \\
\hline Fenofibrate & $0(0)$ & $13(5)$ & 0.005 \\
\hline
\end{tabular}

Values are $\mathrm{n}(\%)$ unless otherwise specified. * Shoulder and hip were not involved in any patients. MTP: metatarsophalangeal; GC: glucocorticoid; NSAID: nonsteroidal antiinflammatory drug.

\section{DISCUSSION}

There have been several notable changes in the clinical presentation of gout over the recent 2 decades. The "typical" presentation of first MTP arthritis (podagra) has become relatively less frequent, and more atypical presentations with small finger joint involvement are now more common. While these findings require confirmation in other cohorts, they suggest that clinicians now have to maintain a high index of diagnostic suspicion, even in situations in which gout would have been considered an unlikely diagnosis. As well, subsequent flares demonstrate similar changes in clinical presentation and are characterized by a significant increase in polyarticular involvement in the more recent cohort. The reasons for the change in the clinical presentation of incident gout as well as subsequent flares is unclear and requires further study. However, the marked change in associated comorbidities (i.e., obesity, cardiovas- cular, and renal disease) along with medication use between the 2 time periods could be related to the changes in gout presentation.

The risk of subsequent flares is an important factor in the clinical assessment and management decisions regarding use of uric acid-lowering therapy aiming at reducing future flare risk $^{13,14,15}$. Data from the current study indicate that roughly $60 \%$ of patients will have at least 1 subsequent flare during the 5 years following their initial diagnosis. While several studies have mentioned a wide range of flare rates (21-65\%) during their followup periods ${ }^{16,17,18,19,20}$, these differences could be attributed to the difference in methodology used along with the case definition used for gout flare in each study. More importantly, the correct timing of starting a patient on uric acid-lowering therapy is still a subject of clinical uncertainty. Many clinicians introduce uric acid-lowering therapy after the second or third flare.

Personal non-commercial use only. The Journal of Rheumatology Copyright (C) 2020. All rights reserved. 

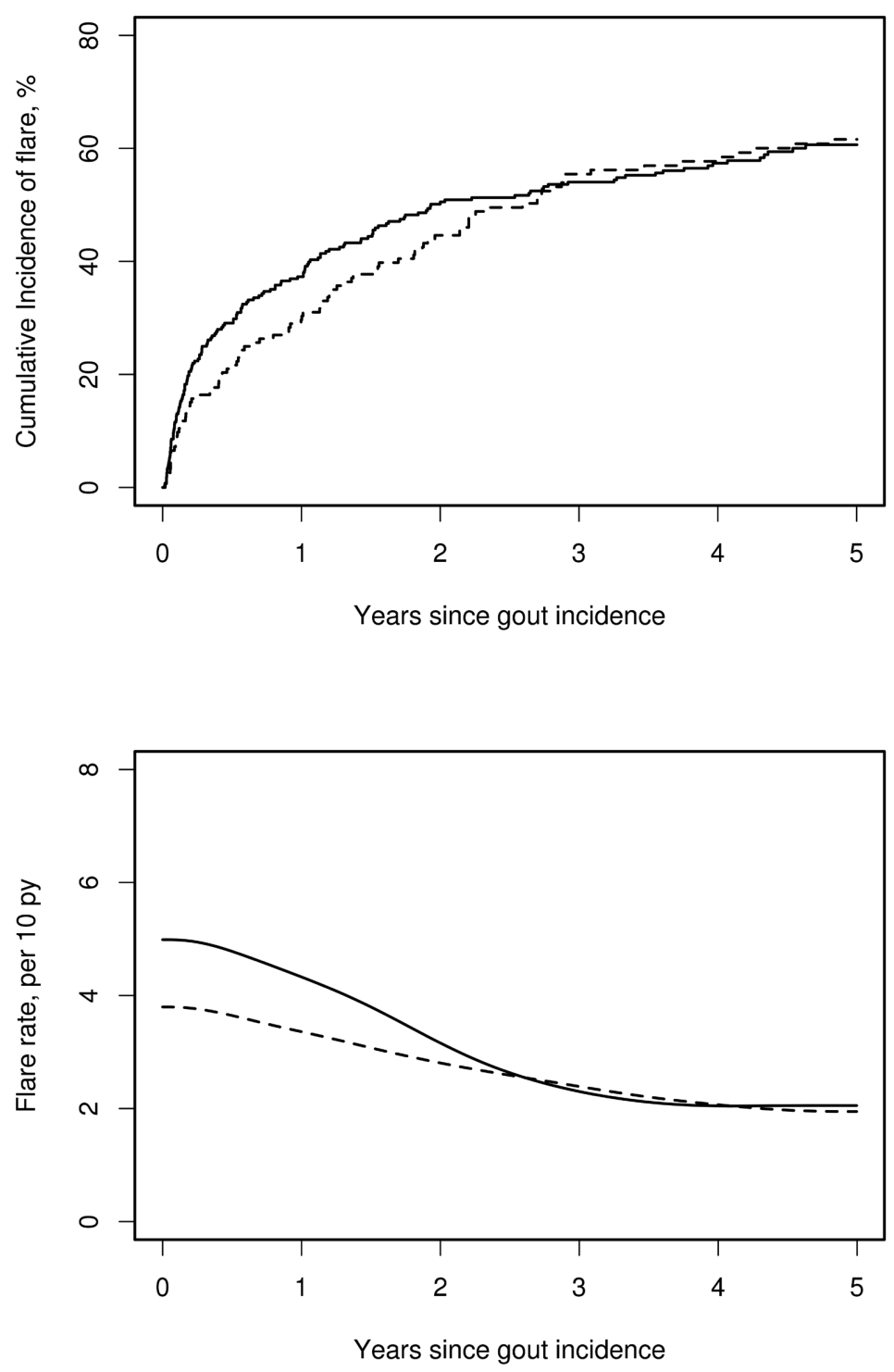

Figure 1. Cumulative incidence of first subsequent flare after gout incidence date (upper panel) and rates of all subsequent flares (lower panel) among patients diagnosed with gout in Olmsted County, Minnesota in 1989-1992 (dashed line) and 2009-2010 (solid line). PY: person-years.

Table 2. Characteristics of first subsequent flare in patients with gout among Olmsted County, Minnesota, residents with incident gout in 1989-1992 compared with 2009-2010.

\begin{tabular}{lccc}
\hline Characteristics & $\begin{array}{c}1989-1992, \\
\mathrm{n}=90\end{array}$ & $\begin{array}{c}2009-2010, \\
\mathrm{n}=158\end{array}$ & $\mathrm{p}$ \\
\hline Podagra & $63(70)$ & $71(45)$ & $<0.001$ \\
Bursitis & $1(1)$ & $8(5)$ & 0.11 \\
No. joints involved & & & $<0.001$ \\
1 & $83(92)$ & $113(75)$ & \\
$2-3$ & $7(8)$ & $16(11)$ & \\
$4+$ & $0(0)$ & $5(3)$ & \\
Unclear & $0(0)$ & $23(11)$ & \\
& & &
\end{tabular}

Values are $\mathrm{n}(\%)$ unless otherwise specified.
However, our data indicate that there are certain high-risk features such as high uric acid levels at baseline and presence of chronic kidney disease, which may justify an early, more aggressive uric acid-lowering approach ${ }^{21}$.

Important strengths of our study include the population-based design, which reduces the risk of referral/selection bias by including virtually all patients in a defined geographic area. Several criteria sets were applied to ascertain incident cases of gout, thereby mitigating the risk of accidentally including patients with other types of inflammatory arthritis. The criteria-based diagnosis of incident gout diagnosis improved the diagnostic accuracy over claims-based or coding-dependent diagnosis ${ }^{22}$. 
Table 3. Predictors of subsequent flares among Olmsted County, Minnesota, residents with incident gout in 1989-1992 compared with 2009-2010 based on univariable models

\begin{tabular}{ll}
\hline Predictors at Gout Incidence & HR $(95 \% \mathrm{CI})$ \\
\hline Diagnosis year 2009-2010 (vs 1989-1992) & $1.14(0.95-1.36)$ \\
Age (per 10-yr change) & $1.01(0.96-1.06)$ \\
Sex, male & $1.16(0.94-1.42)$ \\
$1+$ joints affected & $1.23(0.96-1.59)$ \\
Joint other than first MTP affected & $1.16(0.98-1.38)$ \\
Starting uric acid-lowering therapy & $0.95(0.74-1.22)$ \\
Serum uric acid level & $1.13(1.07-1.19)$ \\
Abnormal serum uric acid ( $\geq 7$ mg/dl for males & \\
$\quad$ and $\geq 6$ mg/dl for females) & $1.59(1.16-2.18)$ \\
BMI $\geq 30 \mathrm{~kg} / \mathrm{m}^{2}$ & $0.96(0.81-1.13)$ \\
Diuretic use & $1.17(0.99-1.38)$ \\
Total cholesterol, per $10 \mathrm{mg} / \mathrm{dl}$ change & $1.00(0.98-1.02)$ \\
Triglycerides, per $10 \mathrm{mg} / \mathrm{dl}$ change & $1.00(0.99-1.01)$ \\
Kidney disease & $1.34(1.12-1.61)$ \\
Hypertension & $1.07(0.90-1.27)$ \\
Diabetes mellitus & $1.16(0.94-1.43)$ \\
Hyperlipidemia & $1.04(0.88-1.23)$ \\
& \\
\hline
\end{tabular}

MTP: metatarsophalangeal; BMI: body mass index.

Limitations of our study are inherent to its retrospective design. The diagnosis of incident gout as well as the recording of subsequent flares and clinical variables is dependent on a non-standardized clinical documentation. Clinical practices and documentation standards have changed over time and may result in systematic differences in the retrieval of clinical information between the 2 cohorts. We tried to mitigate the risk of incomplete case retrieval by using all 3 proposed criteria sets for gout. More recently, new gout criteria have been published, including new imaging modalities such as musculoskeletal ultrasound and dual-energy computed tomography ${ }^{17}$. Because these imaging modalities were not used during the 1989-1992 time period, but were available during the 2009-2010 period, we did not retrospectively apply the new American College of Rheumatology/European League Against Rheumatism criteria to the study cohorts. Similar to several other studies ${ }^{16,17,23,24}$, we used physician determination as the diagnostic criterion for subsequent gout flares. It is possible that subsequent flares were missed if the patient did not seek any provider contact during an acute attack.

Our study suggests that the clinical presentation of gout is changing. This finding adds to the mounting body of evidence that indicates that various aspects of gout, including incidence $2,3,6,16$, prevalence ${ }^{1,3,7,25}$, and associated comorbidities $2,7,26,27$ have transformed over recent decades. We were able to show that the "classic" presentation of gout, inflammatory arthritis of the first MTP joint, has become a relatively less frequent presentation. Conversely, the relative frequency of small finger or foot joint involvement (other than first MTP) has increased and polyarticular flares are now relatively more common.
Our findings quantify the risk of subsequent flares and identify important risk factors such as the extent of hyperuricemia and the presence of renal dysfunction. These findings indicate that clinicians need to maintain a high level of suspicion for gout as a possible cause of joint pain and inflammation in atypical cases of inflammatory arthritis, and to guide the decision of whether a patient should be given uric acid-lowering therapy for flare prophylaxis.

\section{REFERENCES}

1. Zhu Y, Pandya BJ, Choi HK. Prevalence of gout and hyperuricemia in the US general population: the National Health and Nutrition Examination Survey 2007-2008. Arthritis Rheum 2011;63:3136-41.

2. Elfishawi MM, Zleik N, Kvrgic Z, Michet CJ, Crowson CS, Matteson EL, et al. The rising incidence of gout and the increasing burden of comorbidities: a population-based study over 20 years. J Rheumatol 2018;45:574-9.

3. Kuo CF, Grainge MJ, Zhang W, Doherty M. Global epidemiology of gout: prevalence, incidence and risk factors. Nat Rev Rheumatol 2015;11:649-62.

4. Li R, Sun J, Ren LM, Wang HY, Liu WH, Zhang XW, et al. Epidemiology of eight common rheumatic diseases in China: a large-scale cross-sectional survey in Beijing. Rheumatology 2012;51:721-9.

5. Kuo CF, Grainge MJ, See LC, Yu KH, Luo SF, Zhang W, et al. Epidemiology and management of gout in Taiwan: a nationwide population study. Arthritis Res Ther 2015;17:13.

6. Klemp P, Stansfield SA, Castle B, Robertson MC. Gout is on the increase in New Zealand. Ann Rheum Dis 1997;56:22-6.

7. Annemans L, Spaepen E, Gaskin M, Bonnemaire M, Malier V, Gilbert T, et al. Gout in the UK and Germany: prevalence, comorbidities and management in general practice 2000-2005. Ann Rheum Dis 2008:67:960-6.

8. St Sauver JL, Grossardt BR, Yawn BP, Melton LJ 3rd, Rocca WA Use of a medical records linkage system to enumerate a dynamic population over time: the Rochester epidemiology project. Am J Epidemiol 2011;173:1059-68.

9. Wallace SL, Robinson H, Masi AT, Decker JL, McCarty DJ, Yü TF. Preliminary criteria for the classification of the acute arthritis of primary gout. Arthritis Rheum 1977;20:895-900.

10. Ball J, Jeffrey MR, Kellgren J. The epidemiology of chronic rheumatism; volume 2: atlas of standard radiographs of arthritis. Oxford: Oxford Blackwell Scientific Publications; 1963:295.

11. Decker JL. Report from the subcommittee on diagnostic criteria for gout. In: Population studies of the rheumatic diseases. Proceedings of the Third International Symposium, New York, June 5-10, 1966 Amsterdam: Excerpta Medica Foundation; 1968:457.

12. Box-Steffensmeier JM, De Boef S. Repeated events survival models: the conditional frailty model. Stat Med 2006;25:3518-33

13. Richette P, Doherty M, Pascual E, Barskova V, Becce F, Castañeda-Sanabria J, et al. 2016 updated EULAR evidence-based recommendations for the management of gout. Ann Rheum Dis 2017;76:29-42.

14. Hui M, Carr A, Cameron S, Davenport G, Doherty M, Forrester H, et al; British Society for Rheumatology Standards, Audit and Guidelines Working Group. The British Society for Rheumatology guideline for the management of gout. Rheumatology 2017:56:1246.

15. Khanna D, Khanna PP, FitzGerald JD, Singh MK, Bae S, Neogi T, et al. 2012 American College of Rheumatology guidelines for management of gout part II: therapy and anti-inflammatory prophylaxis of acute gouty arthritis. Arthritis Care Res 2012;64:1447-61.

$$
\text { Personal non-commercial use only. The Journal of Rheumatology Copyright @ } 2020 \text {. All rights reserved. }
$$


16. Rothenbacher D, Primatesta P, Ferreira A, Cea-Soriano L, Rodríguez LA. Frequency and risk factors of gout flares in a large population-based cohort of incident gout. Rheumatology 2011;50:973-81.

17. Shoji A, Yamanaka H, Kamatani N. A retrospective study of the relationship between serum urate level and recurrent attacks of gouty arthritis: evidence for reduction of recurrent gouty arthritis with antihyperuricemic therapy. Arthritis Care Res 2004;51:321-5.

18. Wu EQ, Patel PA, Mody RR, Yu AP, Cahill KE, Tang J, et al. Frequency, risk, and cost of gout-related episodes among the elderly: does serum uric acid level matter? J Rheumatol 2009;36:1032-40.

19. Trifirò G, Morabito P, Cavagna L, Ferrajolo C, Pecchioli S, Simonetti M, et al. Epidemiology of gout and hyperuricaemia in Italy during the years 2005-2009: a nationwide population-based study. Ann Rheum Dis 2013;72:694-700.

20. Halpern R, Fuldeore MJ, Mody RR, Patel PA, Mikuls TR. The effect of serum urate on gout flares and their associated costs: an administrative claims analysis. J Clin Rheumatol 2009;15:3-7.

21. Singh JA. Quality of life and quality of care for patients with gout. Curr Rheumatol Rep 2009;11:154-60.

22. Harrold LR, Saag KG, Yood RA, Mikuls TR, Andrade SE, Fouayzi
$\mathrm{H}$, et al. Validity of gout diagnoses in administrative data. Arthritis Rheum 2007;57:103-8.

23. Poiley J, Steinberg AS, Choi Y, Davis CS, Martin RL, McWherter CA, et al; Arhalofenate Flare Study Investigators. A randomized, double-blind, active- and placebo-controlled efficacy and safety study of arhalofenate for reducing flare in patients with gout. Arthritis Rheumatol 2016;68:2027-34.

24. Sarawate CA, Patel PA, Schumacher HR, Yang W, Brewer KK, Bakst AW. Serum urate levels and gout flares: analysis from managed care data. J Clin Rheumatol Pract Rep Rheum Musculoskelet Dis 2006;12:61-5.

25. Helmick CG, Felson DT, Lawrence RC, Gabriel S, Hirsch R, Kwoh CK, et al; National Arthritis Data Workgroup. Estimates of the prevalence of arthritis and other rheumatic conditions in the United States. Part I. Arthritis Rheum 2008;58:15-25.

26. Kuo CF, Grainge MJ, Mallen C, Zhang W, Doherty M. Comorbidities in patients with gout prior to and following diagnosis: case-control study. Ann Rheum Dis 2016;75:210-7.

27. Zhu Y, Pandya BJ, Choi HK. Comorbidities of gout and hyperuricemia in the US general population: NHANES 2007-2008. Am J Med 2012;125:679-87. 